Uluslararası Mühendislik

Cilt/Volume:12 Sayı/Issue:1 Ocak/January 2020

Araştırma Makalesi / Research Article

\title{
Assessment of Mechanical and Thermal Properties of Juniperus Drupacea/Epoxy Biocomposite
}

\author{
Mustafa Taşyürek $^{1 *}$ (iD, Sait Aras $^{2}$ \\ ${ }^{1}$ Selcuk University, School of Civil Aviation, Department of Airframe and Powerplant Maintenance, 42130, Konya, TURKEY \\ ${ }^{I}$ Selçuklu Vocational and Technical Anatolian High School, Motor-Driven Vehicle Technology Area Konya, TURKEY
}

Son Versiyon/Final Version: 31/01/2020

\begin{abstract}
This paper presents experimental data using estimated approach to determine some mechanical properties of epoxy matrix based composites. For this reason, the epoxy matrix was made composite with the powdered materials obtained from different parts of the juniperus drupacea seeds. In order to obtain a homogeneous structure ultrasonic mixing technique was preferred. As an experimental estimation approach, the Taguchi method that is an alternative way to characterize complex composite structures, to come from above the problems and to investigate the effects of test parameters-factors by performing a few experiments was used. In the study, the L9 Taguchi orthogonal array has been preferred. Based on some production conditions; bio-reinforcement material has lowered the average hardness value to 4.22 and formed a more soft structure in addition to improving the tensile strength value by $46 \%$ compared to the neat sample. Parametric study showed that; the most important parameter affecting hardness and tensile strength are the mixing time and reinforcement ratio, respectively.
\end{abstract}

Key Words

“Juniperus Drupacea, Analysis of Variance, Bio-composite, Taguchi Method, Mechanical and Thermal Properties" 


\section{Introduction}

Drupacea is a species of Cupressaceae family. This family represents four subdivisions which were widely spread out and takes place in the family of juniperoidea. This family was located in Juniperus regulations and drupacea using in the juniperus section out following years it was supposed to be taken in Juniperus section. Dönmez (2005)

Drupacea is a tree growing in Mediterranean region with a sea level of 600-1750 metres. Kocakulak (2007) Height ranges of trees is between 10 to $20 \mathrm{~m}$. Drupacea nuts ripen in two years have round shapes and they are green at the beginning. By the time Akkaya (2010) stated that it changes its color to purple and then to brown. Drupacea is an evergreen and dioecious tree. Also according to knowledge obtained from Karaca (2009), the nuts are about 20-25 $\mathrm{mm}$ in diameter.

The polymer composites are often preferred in various applications such as automotive, flooring, aviation, marine and yacht or underwater materials. In that sense, the composite material is expected to be at the top in respect for its thermal, mechanic and wearing affects. The additional reinforcing element to matrix is quiet important for the performance of composites. To strengthen the performance, carbon nanotube, nano-clay, micro or nano fiber, nano-metal powders are used beside glass, carbon, aramid and basalt fibers. (Kara and Kırıcı 2017, Morkavuk et all. 2018, Gemi et all. 2016) However, we come across ambiguity for human health as many nano materials aren't produced naturally. Some bio-composite plates were produced and carried to houses by using various agricultural waste products. Possible changes in the mechanical properties of epoxy have never been studied before in the case of reinforcing of Juniperus drupacea.

As a reinforcement element, peanut shell (Karaağaç 2013, Lamrani et all. 2017), cashew shell (Harini et all. 2018, Kasemsiri et all. 2015), cotton (Alomayri et all. 2014), cacao powder (Imoisili et all. 2013), coconut (Kuburi et all. 2017, Sarki et all. 2011), sun flower seeds (Mati-Baouche et all. 2014), palm (Saba et all. 2016), nut shell powder (Matejka et all. 2013), natural seeds/fibers and bark powders are chosen to be used [16-22]. (Johnson et all. 2005, Alavudeen et all. 2015, Jingqiang et all. 2004, Day et all. 2001, Jumaidin et all. 2016, Saba et all. 2016, Koçak \& Mistık 2015)

Prabhakar et all. (2015) stated that, the production of natural plastic seems to be an important task of scientists. Many articles are in circulation about composite materials that artificially produced. In addition to mechanic and thermal features of bio-composite materials are under investigation. (Fernández et all. 2016, Borchani et all. 2015, Fernandeset all. 2015) However, most of the bio-composite to be in nature haven't been tried yet. One of them is drupacea is becoming important especially on the point of nutrition and it is searched for its physical structure and nutrition. Akbulut et all. 2008, Akınc1 et all. 2004)

Drupacea can be found in great deal in nature although it is regional and is accessible without charge. The nuts can either be ground as a whole or as separated with outer skin and nuts without skin. That makes it easy to use as reinforcing materials in plastic. So, the Juniperus drupacea/epoxy bio-composite would be an interesting and unusual model to find a new bio-composite material. There are no data or study on the mechanical and thermal properties of Juniperus drupacea/epoxy bio-composite so far. For the purpose of reduced of negative environmental effects of plastics, for use as a reinforcing material was carried out to drupacea.

\section{Materials \& Method}

\subsection{Materials}

As a matrix material LR 326 resin is selected and as for hardening LH 265 is used. Epoxy which that is used in high heat applications was provided from a manufacturer company in Turkey. Drupacea nut which that is a reinforcement material, are picked up as plant seeds through collection from the nature. The drupacea nut powder was made by mechanical process.

\subsection{Powder Process}

Drupacea nuts are collected from nature as dried in the sun. They were washed to get rid of dust and dirt on the nuts. Some of the nuts were skinned off with a knife and then skins and nuts were dried again. The production diagram of drupacea powder is given in Figure 1.

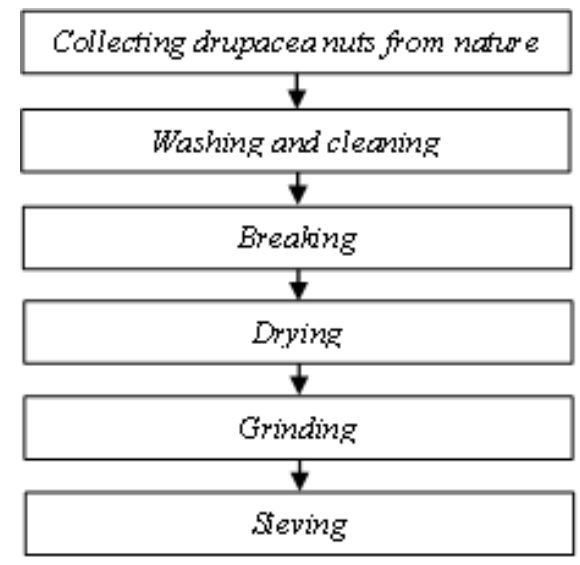

Figure 1. The production diagram of drupacea powder 
The nuts were broken with hummer and then dried. After that, they were ground in the rod-mill to get powder. Finally, the powder was sieved in the thickness of $\leq 1 \mathrm{~mm}$. Drupacea tree, its cone, nuts and powder were given Figure 2.

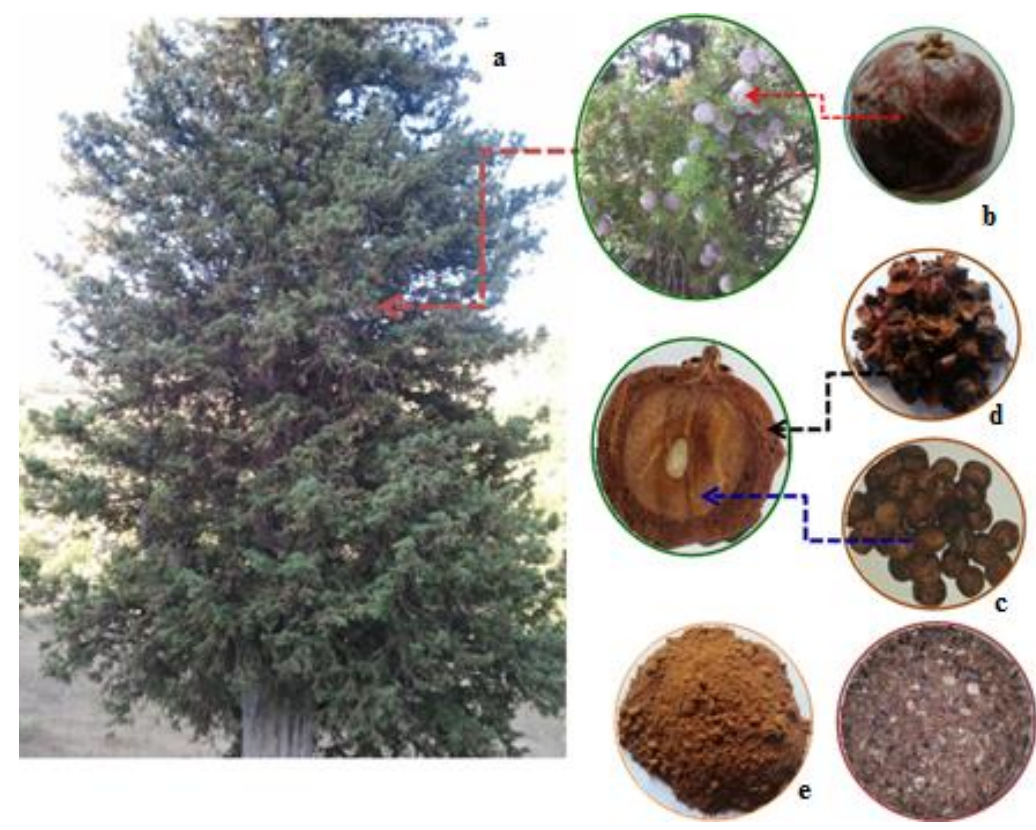

Figure 2. (a) Drupacea tree, (b) drupacea cone, (c) drupacea nut, (d) drupacea nut shell (e) drupacea powder

\subsection{Bio-composites preparation}

The percentages of additional material were varied 1\%,5\%,10\%. The viscosity was reduced to obtain homogenizing before adding weighed powder materials to matrix. The additional dusts were mixed in matrix with ultrasonically. Mixing time was diversified to 5, 10, 15 minutes. To get rid of air bubbles the temperature was lowered and then the hardener was added. The hardener was stirred mechanically for five minutes. Finally, the mixture was placed inside an oven with iron mould for $1 \mathrm{~h}$ at $80^{\circ} \mathrm{C}$ and $1 \mathrm{~h}$ at $120^{\circ} \mathrm{C}$. The samples taken from moulds and smoothed with sandpaper were prepared for usage according to ASTM D 638.

\subsection{Taguchi / ANOVA Methods}

In this study, the L9 orthogonal array (see Table 2) are applied for epoxy matrix reinforced with Juniperus Drupacea that is called as bio-composite material. Each experiment in the L9 array was repeated three times and the averages of the values were calculated. So, a minimized error was obtained. The effects of the three parameters have been studied for every level as shown in Table 1.

For the system with three factors and with three levels, a full factorial design with 27 experiments is required. However, after the repetition, 27 samples of 81 experiments will cause time and material losses. There are three factors are called A, B, and C. Letters represents reinforcing portion, reinforcing variety and mixture duration, respectively as seen in table 2.

In this study, the DOE procedure using Taguchi approach is implemented for the mechanical and thermal properties of previously unknown bio-composite materials produced via reinforced by Juniperus Drupacea. So, determination of optimum production parameters is very crucial to discover a new bio-composite material. The most important criteria for the Taguchi method is to determine the $\mathrm{S} / \mathrm{N}$ portion in order to analyse the experimental data. In these works it was selected maximum $\mathrm{S} / \mathrm{N}$ rate to determine samples produced in optimum conditions. $\mathrm{S} / \mathrm{N}$ rate was calculated by using number (1) equation.

$S N R=-\log _{10}\left[\frac{1}{n} \sum_{i=1}^{n} \frac{1}{y_{i}^{2}}\right]$

The values studied here are "n" the volume of noise factor, "yi" reaction variant.

Table 1. Parameters and levels

\begin{tabular}{lccc}
\hline Levels/Factors & 1 & 2 & 3 \\
\hline A- Reinforcement percentage (\%) & 1 & 5 & 10 \\
B- Reinforcement variety & shell & nut & cone \\
C- Mixture duration (min.) & 5 & 10 & 15 \\
\hline
\end{tabular}


Table 2. L9 Experimental Design

\begin{tabular}{cccc}
\hline Variables & $\mathrm{A}$ & $\mathrm{B}$ & $\mathrm{C}$ \\
\hline $\mathrm{A}_{1} \mathrm{~B}_{1} \mathrm{C}_{1}$ & 1 & 1 & 1 \\
$\mathrm{~A}_{1} \mathrm{~B}_{2} \mathrm{C}_{2}$ & 1 & 2 & 2 \\
$\mathrm{~A}_{1} \mathrm{~B}_{3} \mathrm{C}_{3}$ & 1 & 3 & 3 \\
$\mathrm{~A}_{2} \mathrm{~B}_{1} \mathrm{C}_{2}$ & 2 & 1 & 2 \\
$\mathrm{~A}_{2} \mathrm{~B}_{2} \mathrm{C}_{3}$ & 2 & 2 & 3 \\
$\mathrm{~A}_{2} \mathrm{~B}_{3} \mathrm{C}_{1}$ & 2 & 3 & 1 \\
$\mathrm{~A}_{3} \mathrm{~B}_{1} \mathrm{C}_{3}$ & 3 & 1 & 3 \\
$\mathrm{~A}_{3} \mathrm{~B}_{2} \mathrm{C}_{1}$ & 3 & 2 & 1 \\
$\mathrm{~A}_{3} \mathrm{~B}_{3} \mathrm{C}_{2}$ & 3 & 3 & 2 \\
\hline
\end{tabular}

\subsection{Mechanical Tests}

For investigation the mechanical properties of bio-composite samples tensile tests were applied. Tests were performed according to relevant test standard ASTM D 638. Hardness values of the nanocomposites samples were evaluated by Vickers HRR hardness test device and these values are also given in Figure 6. The values reported are averages of three measured. The hardness measurement results were obtained from the bottom of the samples.

\section{Results \& Discussion}

\subsection{Tensile Tests}

The result of tensile of samples produced in the method of Taguchi can be seen in figure 3 and figure 4 . Drupacea and the other kinds are observed to change its epoxy values according to chart. On samples with better strength samples have higher strength values of drupacea nut shell powder and whole drupacea nut powders use samples produced with a long mixing time. The shorter the stirring the less resistible the sample is. That's because the reinforcing powders in the matrix aren't homogenized. Besides the samples in which drupacea nuts powders used often give low values. The drupacea nut powder particles are harder and rigid structure than other reinforcing components cause to keep its shape during mixing. As they keep its shape they don't have a large volume in the matrix. The drupacea shell powders, which are capable of doing the opposite and exhibiting more flexible properties, have shown a more ideal approach in terms of homogeneity. Therefore, increase of resistance and more elastic can be explained in that reason. The data obtained from Taguchi method proves this as well.

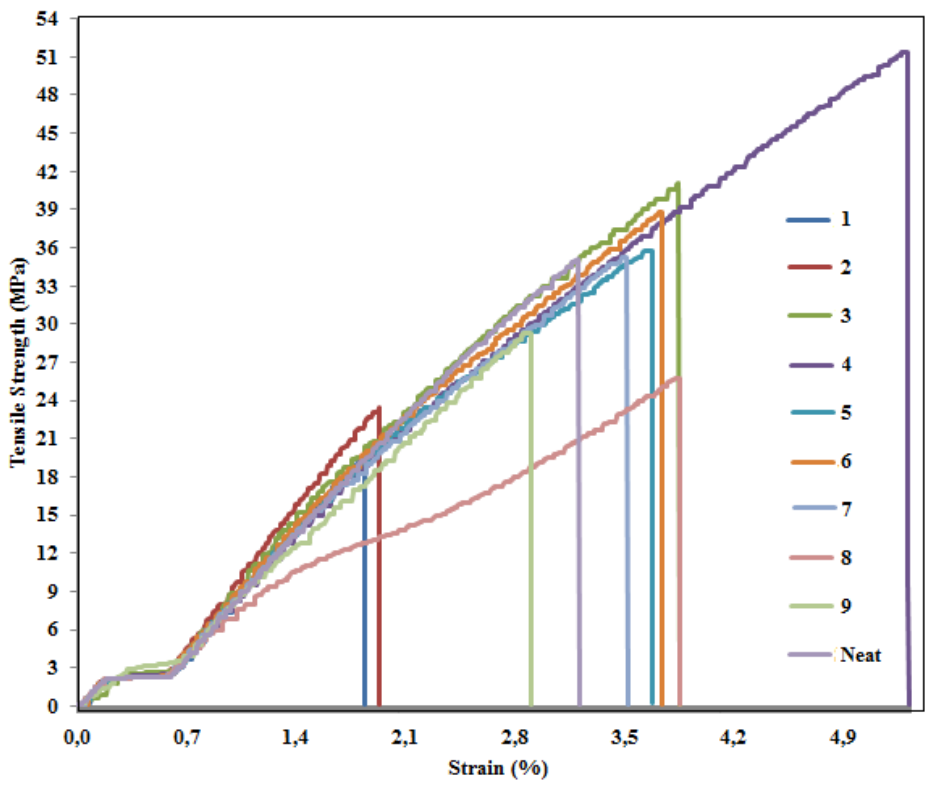

Figure 3. Stress-strain curves for neat and reinforced samples 


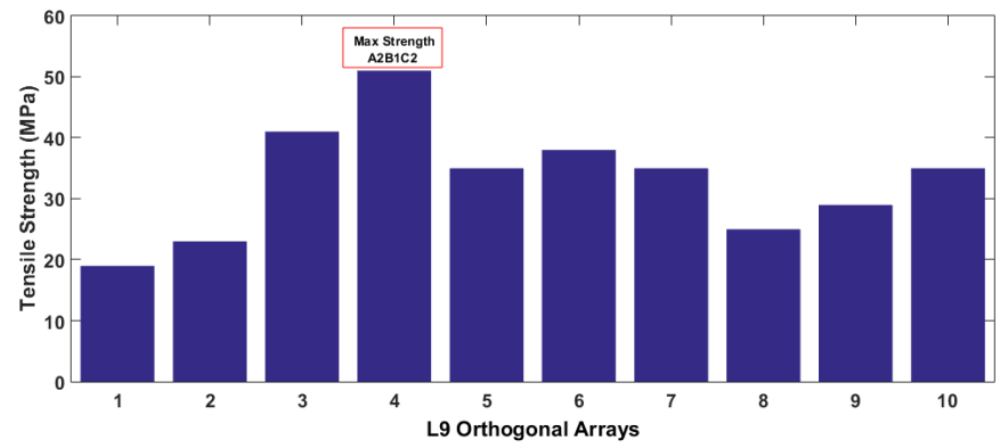

Figure 4. Tensile strength test results of all samples with L9 orthogonal arrays

Figure 5 shows the elasticity modulus of neat epoxy, and epoxy resin modified with Juniperus Drupacea and its different dusts. It is clearly seen that no increase was observed resulted in elasticity modulus modification. As seen in figure 5, the highest elasticity modulus among the modified samples is obtained when reinforcement $10 \%$, drupacea shell powder reinforcement and maximum stirring were used simultaneously. However, reinforced material's values haven't had a rise when compared with pure epoxy in elasticity values. Sample with number 7 shows quite simple increase. When we look at the production conditions we can see that the increase of reinforcing percentage and stirring can affect the elastic module positively. The use of whole drupacea cone powder seems to have an effect on decreasing the elasticity modulus due to the negative effect of the simultaneous distribution of the drupacea nut and drupacea nut shell powder in the matrices.

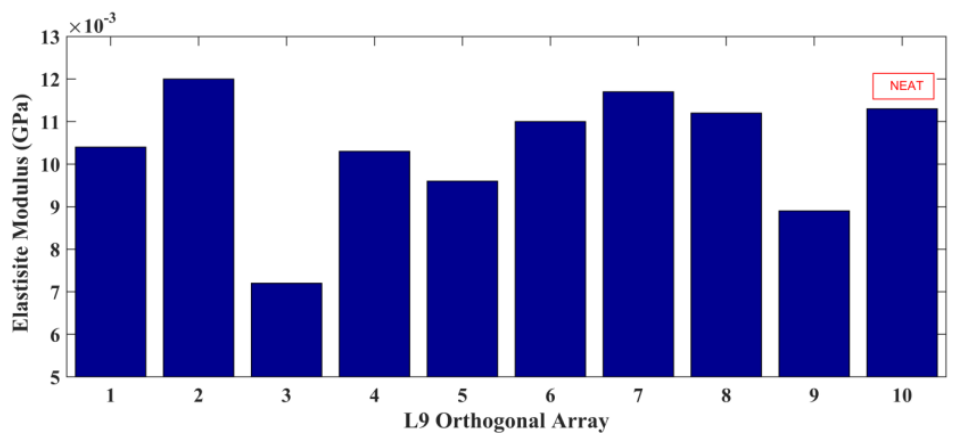

Figure 5. Elastic modulus test results of all samples with L9 orthogonal array

\subsection{Hardness Test:}

The hardness values are scaled in Rockwell R scale. Epoxies are a plastic material resistant to external effects with high strength and hardness. Reducing epoxy hardness with reinforcing materials, the consistency can be increased. According to hardness values; although the sample 2 shows near hardness values, all reinforcing materials when compared with epoxy hardness value came down. Although the use of drupacea nut powder resulted in a hardness value close to that of pure epoxy, the results were slightly lower. The use of drupacea nut shell powder and whole drupacea cone powder as reinforcing material further reduced the hardness value.

The decrease in hardness value in the majority of reinforced materials can be explained by the increased toughness. The stressstrain curves given in figure 3 are generally indicative of increased toughness of the composite samples, except some samples. The increase of the reinforcement ratio in the whole drupacea cone powder and drupacea nut shell powder used samples slightly increased the hardness value.

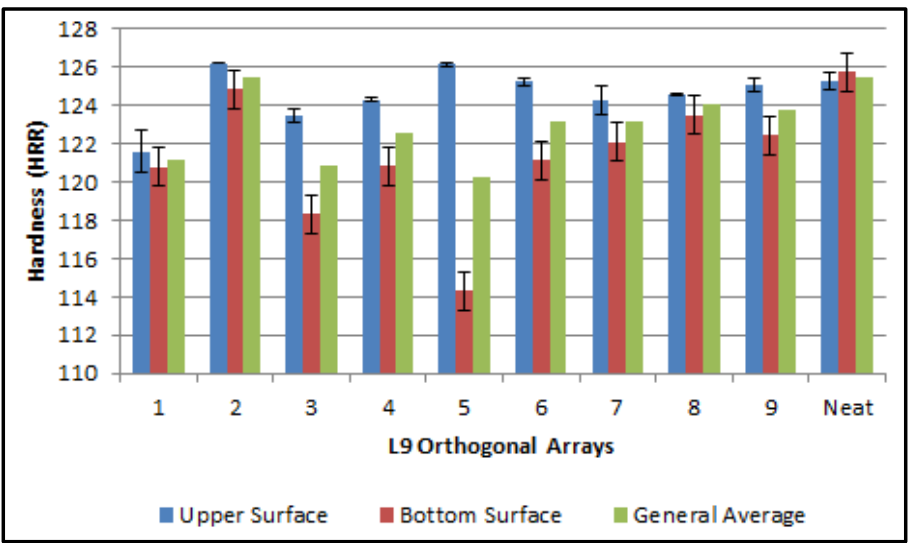

Figure 6. HRR hardness values of experimental specimens 


\subsection{Analysis of Variance}

\subsubsection{Evaluation for Tensile Tests}

The average of $\mathrm{S} / \mathrm{N}$ rate obtained from the experimental designs in table 3 is given in figure 7 . The most important criterion in Taguchi method is to calculate $\mathrm{S} / \mathrm{N}$ rates [9]. The optimum level of parameters in this study realizes in the highest point of $\mathrm{S} / \mathrm{N}$ rates. The optimum production conditions are found for the best tensile values are given below. As seen in figure 7; 5\% of $2 \mathrm{nd}$ level reinforcement $\left(A_{2}\right)$, 3rd level the whole cone $\left(B_{3}\right)$ of stirring level of 15 minutes $(C 3)$ is the optimum design parameters for this experiment $\left(\mathrm{A}_{2} \mathrm{~B}_{3} \mathrm{C}_{3}\right)$.

Table 3. Table of $\mathrm{S} / \mathrm{N}$ values for stress values

\begin{tabular}{ccrr}
\hline Level/Factor & A & \multicolumn{1}{c}{ B } & \multicolumn{1}{c}{ C } \\
\hline 1 & 28,09 & 35,39 & 28,06 \\
2 & 41,93 & 28,29 & 34,69 \\
3 & 30,06 & 36,40 & 37,33 \\
$\Delta$ & 13,84 & 8,11 & 9,27 \\
\hline
\end{tabular}

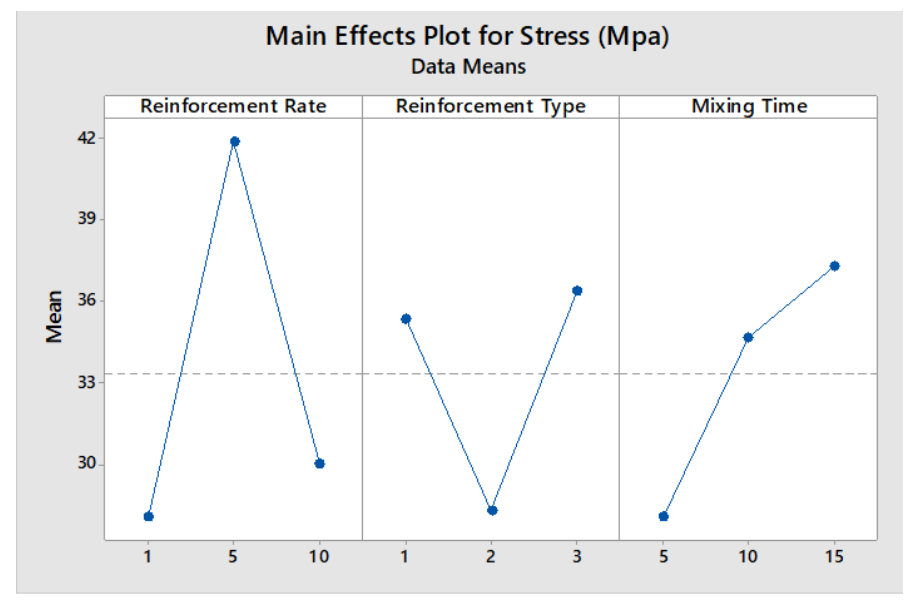

Figure 7. S/N graphic prepared for L9 array

The experimental results and predicted mechanical properties are shown in table 4. Each predicted results haven't gone out of borders of experimental results. According to results one can said, there is a close relationship between the values when the results of the test are compared with the predicted values of Taguchi approach.

Table 4. Predicted and experimental results of epoxy/ Juniperus drupacea nanocomposites from experiments

\begin{tabular}{ccc}
\hline Properties & Estimated data & Test results \\
\hline Tensile strength $(\mathrm{MPa})$ & 19.69 to 45.29 & 19.69 to 51.30 \\
Strain at break $(\%)$ & 1.51 to 4.58 & 1.16 to 5.31 \\
Hardness & 121.10 to 124.75 & 120.22 to 125.52 \\
Elasticity Modulus $(\mathrm{GPa})$ & 0.008 to 0.011 & 0.007 to 0.012 \\
\hline
\end{tabular}

\subsubsection{Evaluation for Hardness Tests}

It is seen that in previous research; participating reinforcement materials at very low ratio does not change tensile strength of the plastic matrix composites significantly. This situation is clearly seen in S/N ratio graphs. According to values between levels of the parameters (see Figure 8.), angle is steeper for mixing time parameter. This is evidence that the mixing time receives the first order in the effectiveness ranking on hardness. The most important factor for obtaining a homogeneously mixed composite material is mixing time. $\Delta$ values in the Table 5 also confirm this situation. Following mixing time, reinforcement rate takes second place in terms of efficacy. The reinforcement type has the least activity. 
Table 5. Table of $\mathrm{S} / \mathrm{N}$ values for hardness values

\begin{tabular}{crrr}
\hline Level/Factor & \multicolumn{1}{c}{ A } & \multicolumn{1}{c}{ B } & \multicolumn{1}{c}{ C } \\
\hline 1 & 122,52 & 122,30 & 122,80 \\
2 & 121,99 & 123,25 & 123,94 \\
3 & 123,65 & 122,60 & 121,41 \\
$\Delta$ & 1,66 & 0,95 & 2,53 \\
\hline
\end{tabular}

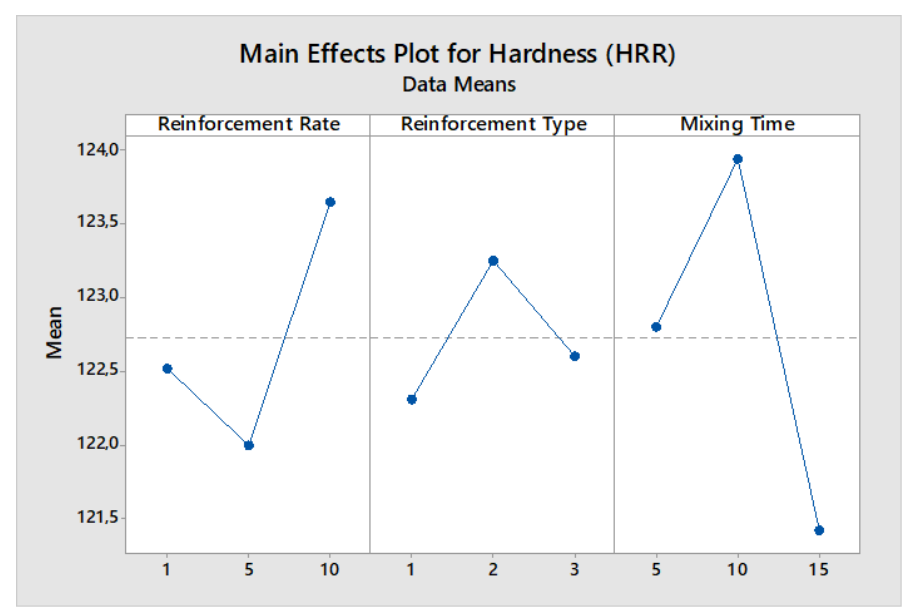

Figure 8. Main Effect Plot for Hardness (HRR)

\subsubsection{Interaction Plots}

Relying on information assessment results of ANOVA program, interaction of production parameters was explained. The use of all types of reinforcing powders according to figure 9 (a) increases the tensile strength of $1 \%$ samples. However, tensile strength value of samples with 5 and $10 \%$ is being more positively affected than drupacea nut shell powder usage. In Figure 9 (b), the 15minute mixing time superior improves the tensile strength of samples with $1 \%$ and $10 \%$ reinforcement, and in 5\% samples, these values peak at 10 minutes of mixing time. Figure 9 (c) and (d) shows the affection of reinforcing kind in orders with mixing rate and time, respectively.

It can be said that the use of whole cone powder is most favourably affected by the $1 \%$ reinforcement ratio, while the $5 \%$ reinforcement ratio is generally more dominant. It also appears that a 15 minute long mixing time increases the tensile strength in the use of drupacea nut powder and drupacea cone powder.

The values of the mixing time with respect to the reinforcing filler are similar to those of the reinforcing filler according to the reinforcement ratio. Also, usage of drupacea nut shell powder with 10 minute mixing time shows the much better effect. In general, the use of whole fruit powder seems to be more effective when the stress values of the samples produced for 5 and 15 minutes are examined. 


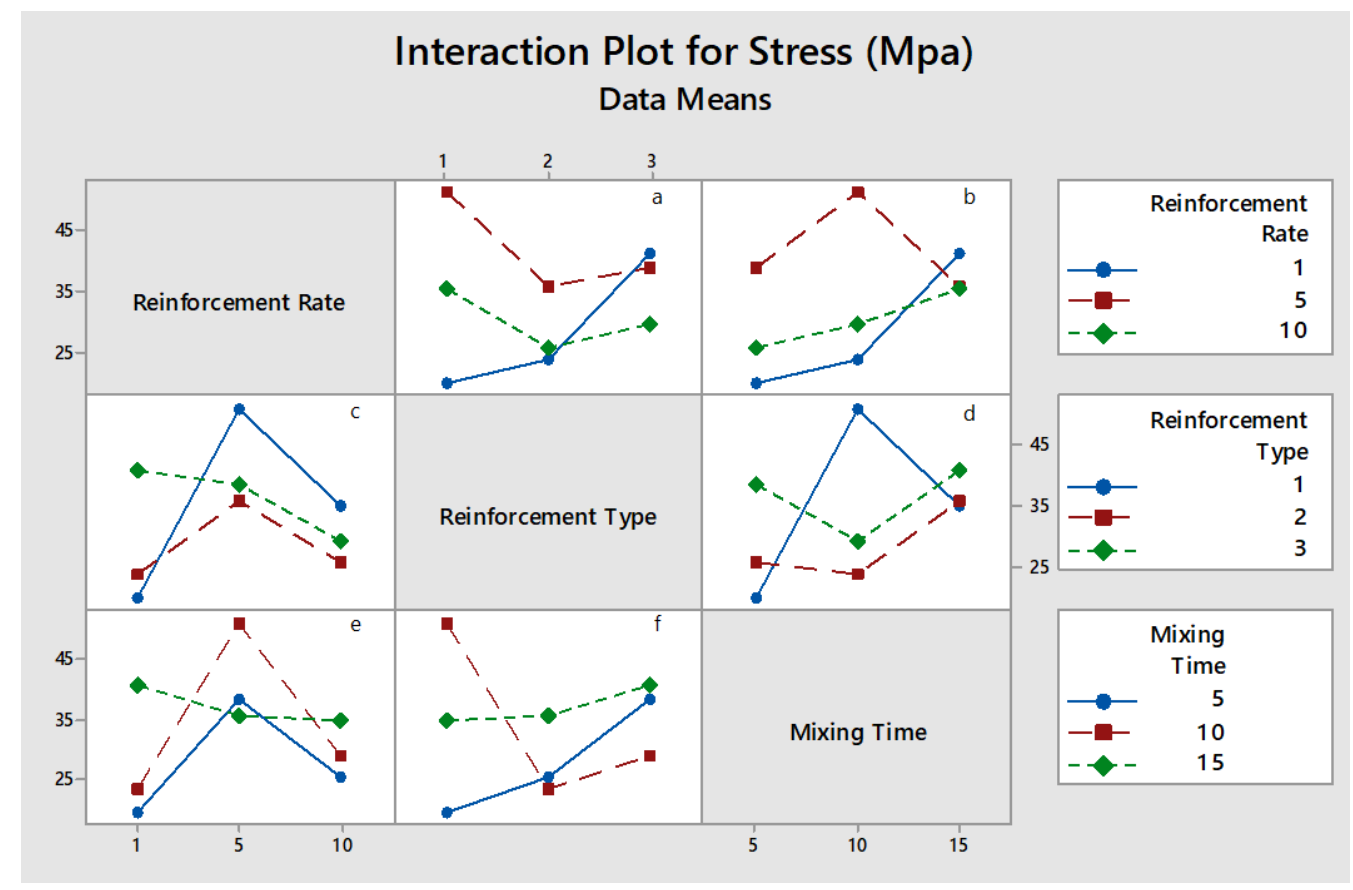

Figure 9. The results of interaction of all parameters of samples with each other (a) The state of being affected by the kind of the reinforcement ratio (b) The state of being affected by the mixing time of the reinforcement ratio (c) Influence of the reinforcement type on the reinforcement rate (d) Influence of the reinforcement type on the agitation time (e) Effect of the mixing time on the reinforcement rate (f) The influence of the mixing time on the reinforcement type

In figure 10 binary influences of parameters can be seen. In figure 10 we can see; drupacea nut shell powder and the whole drupacea cone powder have positive effect on hardness whereas the drupacea nut powder shows a linear effect. It gives highly hardness values so long as the reinforcing rate is kept stable in whole drupacea cone powders. But in lower reinforcement usage of drupacea nut powder it gives maximum result.

In figure 10 (b), it is seen how reinforcing powders are affected by mixing times and affect the hardness of drupacea/epoxy biomaterials. According to this, as the mixing time increases, the hardness values of the materials formed by the reinforcements in all ratios decrease. Although the maximum hardness value is measured from the sample obtained from the medium mixing period and the low-rate reinforcements, in general, the increase of the reinforcement ratio affects the hardness increasing direction. According to figure 10 (c); drupacea nut shell powder and whole drupacea cone powder from reinforcement types give close values at each reinforcement rate. Keeping the reinforcing rate at $10 \%$ it gave high hardness with no bound to reinforcing sort. In Figure 10 (d), the hardness values obtained from all the reinforcement ratios increase as the time from the low mixing time to the middle mixing time increases, but the hardness values of the samples obtained using the other reinforcement types except for the samples using drupacea nut shell powder are remarkably decreased at high mixing times. If the mixing time is kept stable, in lower and medium mixing time, drupacea nut powder gives high hardness values. The fact that drupacea nut has higher individual rigidity than drupacea nut shell leads to an increase in the stiffness of the biocomposite material. In figure 10 (e) and (f), it shows stable reinforcing rate and types the effect of stirring time on hardness. If high reinforcement ratio is preferred, hardness values close to each other are obtained. In other reinforcing rates, the increase of stirring time caused the decrease of hardness value. In addition, under lower and medium mixing times, drupacea nut powder strengthened the hardness. 


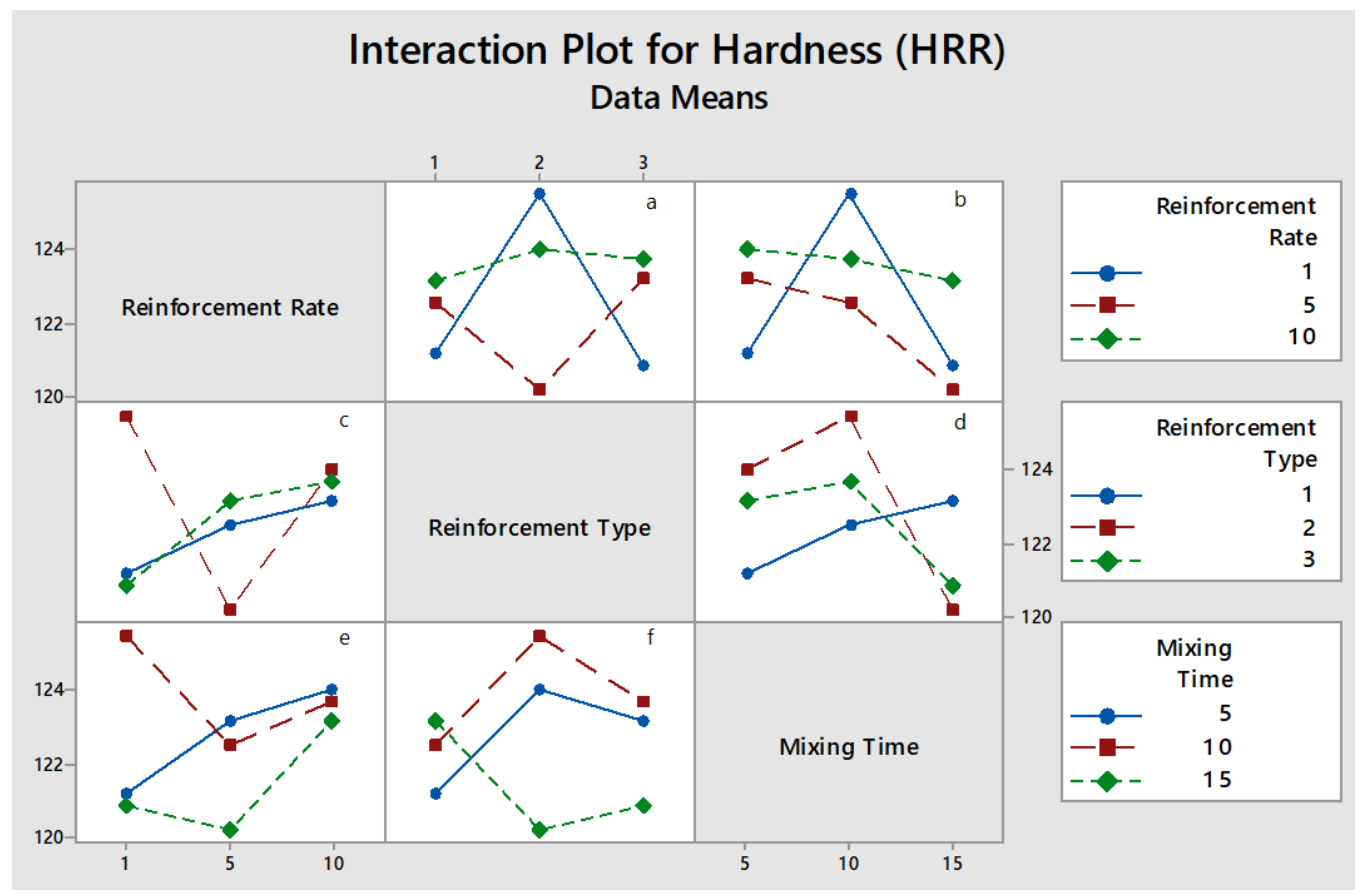

Figure 10. The results of interaction of all parameters of samples with each other (a) The state of being affected by the kind of the reinforcement ratio (b) The state of being affected by the agitation time of the reinforcement ratio (c) Influence of the reinforcement type on the reinforcement rate (d) Influence of the reinforcement type on the agitation time (e) Effect of the mixing time on the reinforcement rate (f) Effect of the mixing time on the reinforcement type.

\section{Conclusions}

A casting mould method has been used to prepare Juniperus Drupacea/epoxy biocomposites. The Juniperus Drupacea core, Juniperus Drupacea fruit shell and cone were dispersed separately into the matrix by ultrasonic technique. The following conclusions are derived from the above reported studies:

- In this work, good results in term of tensile strength have been obtained even using dust of different parts of Juniperus Drupacea.

- The hardness of matrix was reduced by strengthening the whole drupacea parts. By this way the material toughness was increased with some samples.

- The usage of whole drupacea and its shell tighten the tensile strength and elasticity module on the other hand the nut strengthens the hardness.

- Along the analysis program, optimum production conditions are A2B3C3 in order to increase the shrinkage resistance, this value for hardness is A3B2C2.

- When high reinforcement rate is preferred the resistance of material increases independently from reinforcing item.

- When compared experimental results with estimated results, there is a good proximity between values.

- Although reinforcing rate factor is very effective in respect of resistance value, stirring time played more dominant role for the hardness.

\section{Acknowledgment}

Thank you to Konya Technical University, Faculty of Engineering and Natural Sciences, Department of Mining Engineering and also, Assoc. Prof. Elif EREN GÜLTEKIN from Selcuk University, Faculty of Civil Aviation, Department of Airframe Engine Maintenance for their support.

\section{References}

Akbulut, M., Çoklar, H., \& Özen, G., (2008). Rheological Characteristics of Juniperus drupacea Fruit Juice (pekmez) Concentrated by Boiling. Food Science and Technology International, 14, 321-328. https://doi.org/10.1177/1082013208097193 
Akıncı, I., Özdemir, F., Topuz, A., Kabaş, O., \& Çanakçı, M., (2004). Some physical and nutritional properties of Juniperus drupacea fruits. Journal of Food Engineering, 65, 325-331. https://doi.org/10.1016/j.jfoodeng.2004.01.029

Akkaya, Z., (2010). Characterisation of the product obtained by drying of pekmez, MSc. dissertation, Ege University İzmir, TURKEY.

Alavudeen, A., Rajini, N., Karthikeyan, S., Thiruchitrambalam M., \& Venkateshwaren, N., (2015). Mechanical properties of banana/kenaf fiber-reinforced hybrid polyester composites: Effect of woven fabric and random orientation. Materials \& Design, 66, 246-257. https://doi.org/10.1016/j.matdes.2014.10.067

Alomayri, T., Shaikh F.U.A., \& Low, I.M., (2014). Effect of fabric orientation on mechanical properties of cotton fabric reinforced geopolymer composites", Materials \& Design, 57, 360-365. https://doi.org/10.1016/j.matdes.2014.01.036

Borchani, K.E., Carrot C., \& Jaziri, M., (2015). Biocomposites of Alfa Fibers Dispersed in the Mater-Bi® Type Bioplastic: Morphology, Mechanical And Thermal Properties. Composites Part A: Applied Science and Manufacturing, 78, 371-379. https://doi.org/10.1016/j.compositesa.2015.08.023

Day, R.J., Lovell, P.A., \& Wazzan, A.A., (2001). Toughened carbon/epoxy composites made by using core/shell particles. Composites Science and Technology, 61, 41-56. https://doi.org/10.1016/S0266-3538(00)00169-X

Dönmez, İ.E., (2005). Studies on the chemical compositions of syrian juniper (Arceuthos drupacea Ant. et. Kotschy), MSc dissertation, University of Zonguldak Karaelmas, Zonguldak, TURKEY.

Fernández, J.A., Le Moıgne, N., Caro-Bretelle, A.S., El Hage, R., Le Duc, A., Lozachmeur, M., Bono, P., \& Bergeret, A., (2016). Role Of Flax Cell Wall Components On The Microstructure And Transverse Mechanical Behaviour of Flax Fabrics Reinforced Epoxy Biocomposites, Cork-Polymer Biocomposites: Mechanical, Structural And Thermal Properties. Industrial Crops and Products, 85, 93-108.

Fernandes, E.M., Correlo, V.M., Mano, J.F., \& Re1s, R.L., (2015). Cork-Polymer Biocomposites: Mechanical, Structural and Thermal Properties. Materials \& Design, 82, 282-289. https://doi.org/10.1016/j.matdes.2015.05.040

Gemi, L., Kara, M., \& Avci A., (2016) Low velocity impact response of prestressed functionally graded hybrid pipes. Composites Part B: Engineering, 106 (1), 154-163. https://doi.org/10.1016/j.compositesb.2016.09.025

Harini, K., Mohan, C.C., Ramya, K., Karthıkeyan, S., \& Sukumar, M., (2018). Effect of Punica granatum peel extracts on antimicrobial properties in Walnut shell cellulose reinforced Bio-thermoplastic starch films from cashew nut shells. Carbohydrate Polymers, 184, 231-242. https://doi.org/10.1016/j.carbpol.2017.12.072

Imoisili, P.E., Ezenwafor, T.C., Attah Daniel, B.E., \& Olusunle, S.O.O., (2013). Mechanical Properties of Cocoa-Pod/Epoxy Composite; Effect of Filler Fraction. American Chemical Science Journal, 3(4): 526-531. DOI : 10.9734/ACSJ/2013/5526

Johnson, M., Tucker, N., Barnes S., \& Kirwan, K., (2005). Improvement of the impact performance of a starch based biopolymer via the incorporation of Miscanthus giganteus fibres. Industrial Crops and Products, 22, $175-186$. https://doi.org/10.1016/j.indcrop.2004.08.004

Jingqiang, S., Yafeng, Z., Jindong, Q., \& Jianzheng, K., (2004). Core-shell particles with an acrylate polyurethane core as tougheners for epoxy resins. Journal of Materials Science, 39 (20), 6383-6384. DOI: 10.1023/B:JMSC.0000043763.65417.4f

Jumaidin, R., Sapuan, S.M., Jawa1d, M., Ishak, M.R., \& Saharı, J., (2016). Characteristics of thermoplastic sugar palm Starch/Agar blend: Thermal, tensile, and physical properties. International Journal of Biological Macromolecules, 89, 575-581. https://doi.org/10.1016/j.ijbiomac.2016.05.028

Kara, M., \& Kırıc1, M., (2017). Effects of the number of fatigue cycles on the impact behavior of glass fiber/epoxy composite tubes. Composites Part B: Engineering, 123, 55-63. https://doi.org/10.1016/j.compositesb.2017.04.021

Karaca, İ., (2009). Determination of vitamin and mineral in fruit juice concentrates, MSc dissertation, İnönü University, Malatya, TURKEY.

Karaağaç, B., (2013). Use of Ground Pistachio Shell as Alternative Fillerin Natural Rubber/Styrene-Butadiene Rubber-Based Rubber Compounds. Polymer Composites, 35, 2. 245-252. https://doi.org/10.1002/pc.22656

Kasemsiri, P., Neramittagapong A., \& Chindaprasirt, P., (2015). Effect of cashew nut shell liquid on gelation, cure kinetics, and thermomechanical properties of benzoxazine resin. Thermochimica Acta, 600, 20-27. https://doi.org/10.1016/j.tca.2011.03.020 
Kocakulak, E., (2007). Researches on the essential oils of Juniperus drupacea Lab., PhD. dissertation, Gazi University, Ankara, TURKEY.

Koçak, D., \& Mistık, S.I., (2015). The use of palm leaf fibres as reinforcements in composites. Biofiber Reinforcements in Composite Materials, 1st Ed., (pp. 273-281), Woodhead Publishing, Chapter 9, İstanbul,

Kuburi, L.S., Dauda, M., Obada, D.O., Umaru, S., Dodoo-Arhın, D., Iliyasu, I., Balogun, M.B., \& Mustapha, S., (2017). Effects of Coir Fiber Loading on the Physio-mechanical and Morphological Properties of Coconut Shell Powder Filled Low Density Polyethylene Composites. Procedia Manufacturing, 7, 138-144. https://doi.org/10.1016/j.promfg.2016.12.036

Lamrani, M., Laaroussi, N., Khabbazi, A., Khalfaoui, M., Garoum, M., \& Feiz, A., (2017). Experimental study of thermal properties of a new ecological building material based on peanut shells and plaster. Case Studies in Construction Materials, 7 , 294-304. https://doi.org/10.1016/j.cscm.2017.09.006

Matejka, V., Fu, Z., Kukutschová, J., Qi, S., Jiang, S., Zhang, X., Yun, R., Vaculík, M., Heliová, M., \& Lu, Y., (2013). Jute fibers and powderized hazelnut shells as natural fillers in non-asbestos organic non-metallic friction composites. Materials \& Design, 51, 847-853. https://doi.org/10.1016/j.matdes.2013.04.079

Mati-Baouche, N., De Baynast, H., Lebert, A., Sun, S., Lopez-Mingo, C.J.S., Leclaire, P., \& Michaud, P., (2014). Mechanical, thermal and acoustical characterizations of an insulating bio-based composite made from sunflower stalks particles and chitosan. Industrial Crops and Products, 58, 244-250. https://doi.org/10.1016/j.indcrop.2014.04.022

Morkavuk, S., Köklü, U., Bağc1, M., \& Gemi, L., Cryogenic machining of carbon fiber reinforced plastic (CFRP) composites and the effects of cryogenic treatment on tensile properties: A comparative study. Composites Part B: Engineering, $147,1-11$. https://doi.org/10.1016/j.compositesb.2018.04.024

Prabhakar, M.N., Shah, A.R., Chowdoji Rao, K., \& Song, J.I., (2015). Mechanical And Thermal Properties of Epoxy Composites Reinforced With Waste Peanut Shell Powder As A Bio-Filler. Fibers and Polymers, 16, 5. DOI: 10.1007/s12221-015-1119-1

Saba, N., Paridah, M.T., Abdan, K., \& Ibrahim, N.A., (2016). Effect of oil palm nano filler on mechanical and morphological properties of kenaf reinforced epoxy composites. Construction and Building Materials, 123, 15-26. https://doi.org/10.1016/j.conbuildmat.2016.06.131

Saba, N., Parıdah, M.T., Abdan K., \& Ibrahım, N.A., (2016). Physical structural and thermomechanical properties of oil palm nano filler/kenaf/epoxy hybrid nanocomposites. Materials Chemistry and Physics, 184, 64-71. DOI: 10.1016/j.matchemphys.2016.09.026

Sarki, J., Hassan, S.B., Aigbodion V.S., \& Oghenevweta, J.E., (2011). Potential of using coconut shell particle fillers in ecocomposite materials. Journal of Alloys and Compounds, 509, 2381-2385. https://doi.org/10.1016/j.jallcom.2010.11.025 